\title{
Geotechnical Earthquake Engineering
}

Géotechnique Symposium in Print 2015

Edited by

Stuart Haigh

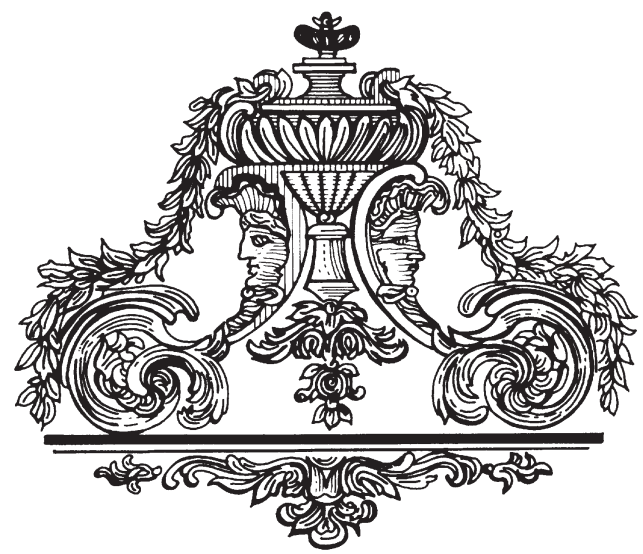


Géotechnique Advisory Panel Sub-Committee for the Symposium in Print 2015:

Dr Stuart Haigh, University of Cambridge, UK

Professor Angelo Amorosi, Politecnico di Bari, Italy

Professor George Gazetas, National Technical University of Athens, Greece

Dr Erdin Ibraim, Bristol University, UK

Professor Boris Jeremic, University of California, Davis, USA

Dr Jonathan Knappett, University of Dundee, UK

Dr Stavroula Kontoe, Imperial College London, UK

Dr William Murphy, University of Leeds, UK

Professor Ellen Rathje, University of Texas at Austin, USA

Professor Ikuo Towhata, University of Tokyo, Japan

Liam Wotherspoon, The University of Auckland, New Zealand

Related titles from ICE Publishing:

Partial Saturation in Compacted Soils (Géotechnique Symposium in Print 2011).

D. Gallipoli (ed). ISBN 978-0-7277-4175-2.

Bio- and Chemo-mechanical Processes in Geotechnical Engineering

(Géotechnique Symposium in Print 2013).

L. Laloui (ed). ISBN 978-0-7277-6053-1.

Earthquake Design Practice for Buildings, third edition.

E.D. Booth. ISBN 978-0-7277-5794-4.

Designers' Guide to Eurocode 8: Design of buildings for earthquake resistance. M.N. Fardis, E. Carvalho, A.S. Elnashai, E. Faccioli, P. Pinto, A. Plumier.

ISBN 978-0-7277-3348-1.

Earthworks: A guide, second edition.

P Nowak, P. Gilbert. ISBN 978-0-7277-5735-7.

ICE Manual of Geotechnical Engineering (2 volumes).

J. Burland, T. Chapman, H. Skinner, M.J. Brown (eds). ISBN 978-0-7277-3652-9.

Core Principles of Soil Mechanics.

S.K. Shukla. ISBN 978-0-7277-5847-7.

ISBN 978-0-7277-6149-1

(C) Thomas Telford Limited 2016

Papers extracted from Géotechnique (C) Authors and Institution of Civil Engineers

All rights, including translation, reserved. Except as permitted by the Copyright, Designs and Patents Act 1988, no part of this publication may be reproduced, stored in a retrieval system or transmitted in any form or by any means, electronic, mechanical, photocopying or otherwise, without the prior written permission of the Publishing Director, ICE Publishing, 1 Great George Street, London SW1P 3AA.

This book is published on the understanding that the authors are solely responsible for the statements made and the opinions expressed in it and that its publication does not necessarily imply that such statements and/or opinions are or reflect the views or opinions of the publishers. While every effort has been made to ensure that the statements made and the opinions expressed in this publication provide a safe and accurate guide, no liability or responsibility can be accepted in this respect by the authors or publishers.

Commissioning Editor: Laura Marriott

Production Editor: Rebecca Taylor

Market Development Executive: Elizabeth Hobson

Typeset by Manila Typesetting Company

Printed and bound in Great Britain by TJ International Ltd, Padstow 


\section{Preface}

Damage to buildings and infrastructure due to geotechnical failures has been observed in all the major earthquakes of the last half century, causing many thousands of deaths and many billions of dollars of economic damage. Since the 1964 Niigata earthquake, this has resulted in a substantial research effort to understand soil behaviour under cyclic loading, to predict the onset of damaging phenomena such as soil liquefaction and to design foundations and geotechnical systems to survive earthquake loading.

While this research effort has continued for the last fifty years, great advances have recently been made using state of the art laboratory testing, dynamic centrifuge modelling and high quality field investigations of system performance during earthquakes such as those in Christchurch, New Zealand in 2010 and 2011 and the Tohoku earthquake in Japan in 2011. The ability of infrastructure to continue to perform post-earthquake is of particular importance in allowing disaster mitigation efforts to rapidly relieve suffering in the affected areas. It was also shown to play a major role in resisting multi-hazards during the Tohoku earthquake, after which coastal defences already damaged by earthquake shaking were required to resist tsunami loading.

The response to this symposium in print was substantial with abstracts being submitted by authors throughout the world. Following the standard review process of Géotechnique, ten papers have been accepted for publication in this issue of the journal, with several further papers missing the deadline to be ready for publication according to the planned schedule. These remaining papers have been moved to the regular publication process of the journal and will appear in future issues. The papers selected for this symposium cover a wide range of topics, from liquefaction prediction based on site investigation to the interaction between buildings owing to coupling through the soil between them. Despite the wide range of subjects, these papers all share the similarity of advancing the current state of the art in geotechnical earthquake engineering research.

This issue was accompanied by a full-day symposium held on 15th June 2015 at the Institution of Civil Engineers (ICE) in London. The symposium included two sessions on field behaviour of soils during earthquakes and model testing of geotechnical systems during earthquakes. The ten papers were all presented by their authors on the day, enabling a wide-ranging discussion to take place around current issues in geotechnical earthquake engineering. The symposium provided an excellent opportunity to discuss the current state of the art in geotechnical earthquake engineering and future opportunities in both research and practice.

This volume also contains three papers published in Géotechnique in 2014 on geotechnical earthquake engineering. These papers, together with those presented during the Symposium in Print are representative of the high quality work on this subject produced by researchers from around the world and published in Géotechnique.

It was my great pleasure to act as chair of the Géotechnique advisory panel subcommittee and to have been guest editor of this issue of Géotechnique. I wish to thank the other members of the subcommittee who have assisted me over the last 18 months for their enormous amount of effort in making this issue and event occur. I would also like to thank all those who have reviewed papers for their thorough and timely reviews. Finally, I would like to thank Craig Schaper, Journals Editor at ICE Publishing, for his great efforts in efficiently organising this issue as well as for his ongoing efforts in making Géotechnique a success.

Stuart Haigh

University of Cambridge, UK

August 2015 
Downloaded by [] on [26/04/23]. Copyright $\odot$ ICE Publishing, all rights reserved. 
Session 1: Field behaviour of soils during earthquakes

Assessment of CPT-based methods for liquefaction evaluation in a Liquefaction Potential Index (LPI) framework

B. W. Maurer, R. A. Green, M. Cubrinovski and B. A. Bradley

Correlation between liquefaction resistance and shear wave velocity of granular soils: a micromechanical perspective

X. M. Xu, D. S. Ling, Y. P. Cheng and Y. M. Chen

An interpretation of the seismic behaviour of reinforced-earth retaining structures

L. Masini, L. Callisto and S. Rampello

Cyclic and dynamic behaviour of a soft pyroclastic rock

L. Verrucci, G. Lanzo, P. Tommasi and T. Rotonda

Empirical predictive relationship for seismic lateral displacement of slopes:

models for stable continental and active crustal regions

J. Lee and R. A. Green

Session 2: Model testing of geotechnical systems during earthquakes

Dynamic response of flexible square tunnels: centrifuge testing and validation of existing design methodologies

G. Tsinidis, K. Pitilakis, G. Madabhushi and C. Heron

Influence of initial stress distribution on liquefaction-induced settlement of shallow foundations D. Bertalot and A. J. Brennan

Seismic structure-soil-structure interaction between pairs of adjacent building structures J. A. Knappett, P. Madden and K. Caucis

A new macro-element model encapsulating the dynamic moment-rotation behaviour of raft foundations

C. M. Heron, S. K. Haigh and S. P. G. Madabhushi

Importance of seismic site response and soil-structure interaction in the dynamic behaviour of a tall building founded on piles

E. Bilotta, L. De Sanctis, R. Di Laora, A. D’Onofrio, F. Silvestri

\section{Related content}

Some remarks on the seismic behaviour of embedded cantilevered retaining walls

R. Conti, G. M. B. Viggiani, and F. Burali D'Arezzo

Revisiting Nigawa landslide of the 1995 Kobe earthquake

H. Ling, H. I. Ling and T. Kawabata

Static and cyclic rocking on sand: centrifuge versus reduced-scale $1 g$ experiments

P. Kokkali, I. Anastasopoulos, T. Abdoun and G. Gazetas 